\title{
Risk factors associated with worse outcomes in COVID-19: a retrospective study in Saudi Arabia
}

\author{
Anas Khan, ${ }^{1,2}$ Saqer Althunayyan, ${ }^{3}$ Yousef Alsofayan, ${ }^{2}$ Raied Alotaibi, ${ }^{4}$ Abdullah Mubarak, ${ }^{4}$ Mohammed Arafat, ${ }^{1}$ Abdullah Assiri ${ }^{5}$ and Hani Jokhdar ${ }^{5}$
}

${ }^{1}$ Department of Emergency Medicine, College of Medicine, King Saud University, Riyadh, Saudi Arabia. ${ }^{2}$ Global Center for Mass Gatherings Medicine, Ministry of Health, Riyadh, Saudi Arabia. ${ }^{3}$ Department of Accident and Trauma, Prince Sultan Bin Abdulaziz College for Emergency Medical Services, King Saud University, Riyadh, Saudi Arabia. ${ }^{4}$ Department of Basic Science, Prince Sultan Bin Abdulaziz College for Emergency Medical Services, King Saud University, Riyadh, Saudi Arabia. ${ }^{5}$ Ministry of Health, Riyadh, Saudi Arabia. (Correspondence to: Yousef Alsofayan: y-m-alsofayan@hotmail.com; yalsofayan@moh.gov.sa).

\begin{abstract}
Background: The rapid emergence of the novel coronavirus disease 2019 (COVID-19) has resulted in millions of infected patients and hundreds of thousands of deaths worldwide. Health care services delivery is being compromised due to the surge in the number of infected patients during this pandemic.
\end{abstract}

Aims: This study aimed to assess the risk factors associated with poor prognosis among COVID-19 patients in Saudi Arabia.

Methods: This was a multi-centre retrospective cohort study that included all laboratory-confirmed COVID-19 cases with definitive outcomes in Saudi Arabia during March 2020. Demographic, clinical history, comorbidity and outcomes data were retrieved from the National Health Electronic Surveillance Network (HESN) database. We used logistic regression models to calculate crude and adjusted odds ratios (OR) to explore risk factors for critical outcomes (intensive care unit admission or death) among COVID-19 cases.

Results: We included 648 COVID-19-positive patients with a median age of 34 years. Of these, 11.9\% were in the critical group. Risk factors associated with worse outcomes included males (OR=1.92), age $>60$ years $(\mathrm{OR}=3.65)$, cardiac diseases $(\mathrm{OR}=3.05)$, chronic respiratory diseases $(\mathrm{OR}=2.29)$, and cases with two or more comorbidities $(\mathrm{OR}=2.57)$ after adjusting for age and sex; all had significant $P$-values $<0.05$.

Conclusions: Independent risk factors for critical outcomes among COVID-19 cases include old age, males, cardiac patients, chronic respiratory diseases, and the presence of two or more comorbidities. We recommend designing a unique multi-item scale system to prognosticate COVID-19 patients.

Keywords: COVID-19, risk factors, ICU admission, mortality, Saudi Arabia

Citation: Khan A; Althunayyan S; Alsofayan Y; Alotaibi R; Mubarak A; Arafat M; et al. Risk factors associated with worse outcomes in COVID-19: a retrospective study in Saudi Arabia. East Mediterr Health J. 2020;26(11):1371-1380. https://doi.org/10.26719/emhj.20.130

Received: 24/06/20; accepted: 14/09/20

Copyright ( World Health Organization (WHO) 2020. Open Access. Some rights reserved. This work is available under the CC BY-NC-SA 3.0 IGO license (https://creativecommons.org/licenses/by-nc-sa/3.o/igo).

\section{Introduction}

The rapid emergence of the novel Coronavirus Disease 2019 (COVID-19) has resulted in millions of infected patients and hundreds of thousands of deaths worldwide. In Saudi Arabia, the total number of confirmed COVID-19 cases as of 13 June 2020 reached 123308 confirmed cases and 932 deaths and is increasing daily (1). Its spread is becoming difficult to control and efforts should focus on effective mitigation measures to minimize the disease impact on those prone to developing adverse outcomes.

Internationally, health-care services delivery is being compromised due to the surge in the number of infected patients during this COVID-19 pandemic. Overwhelming the health-care system will lead to an unexpected rise in morbidity and mortality of various treatable conditions. Therefore, it is critical to risk stratify COVID-19 patients based on their predicted outcomes and guide appropriate management and disposition accordingly.
The clinical manifestation of COVID-19 is broad and ranges from asymptomatic and mild upper respiratory tract symptoms to severe illnesses with multiorgan failure and death (2-4). Furthermore, it is challenging to predict the clinical course or determine patients at risk of deterioration. Previous reports showed that old age and male gender are risk factors for disease severity and mortality $(5,6)$. Other medical comorbidities are associated with poor prognoses such as cardiovascular disease, diabetes mellitus, chronic respiratory disease, and hypertension $(7,8)$. Moreover, distinct signs and symptoms or even laboratory findings are correlated with worse outcomes (5). Nevertheless, these studies' results are difficult to generalize in the Eastern Mediterranean Region because the reported clinical predictors of mortality were studied in different population groups, and clinical characteristics can be different (9).

In this cohort study, we assessed the risk factors of ICU admission or death among COVID-19 patients 
in Saudi Arabia including clinical features, common comorbidities, and a number of laboratory findings.

\section{Methods}

This retrospective cohort study collected data from all laboratory-confirmed COVID-19 cases located in health care facilities across all regions of Saudi Arabia in March 2020. Health-care facilities are mandated to enter the demographic, clinical, laboratory and outcomes data of COVID-19-positive patients in the National Health Electronic Surveillance Network (HESN) database by the health-care providers under the supervision of the Ministry of Health (MoH). All confirmed cases of COVID-19 were screened and only patients with definitive outcomes were included; those in the active phase were excluded.

Demographic, clinical, laboratory, comorbidity, and outcomes data of COVID-19 positive patients were retrieved from the HESN database and extracted into electronic sheets by two data collectors. Any discrepancies were solved by a 3 rd independent reviewer based on the medical reports. In parallel with the World Health Organization (WHO) protocols, COVID-19 was diagnosed based on the results of quantitative RT-PCR testing from nasopharyngeal samples (10). We analyzed age in three different forms: continuous, binary and 20year intervals based on the risk stratification for severe disease in patients with COVID-19 (11). Fever was defined as a temperature of 38 a $\mathrm{C}$ or higher, high respiratory rate was defined as more than 24 breaths per minute and low oxygen saturation was defined as less than $94 \%(5,9,12)$. Comorbidities were classified based on the International Classification of Diseases, Revision 10 (ICD-10) diagnostic codes, then we reported any comorbidity, one or more comorbidity, and two or more comorbidities $(8,13)$. Lymphocytopenia was defined as a lymphocyte count of less than 1500 per cubic millimetre (14).

The primary endpoint of our study was ICU admission, death or recovery. The secondary endpoint was the inhospital length of stay (LOS) in days. Patients included in our study were classified into critical and non-critical groups. Critical cases were defined as patients with ICU admission or death. Non-critical cases were defined as recovered patients with hospital discharge without ICU admission in accordance with $\mathrm{MoH}$ coronavirus disease guidelines (15). This study was approved by the $\mathrm{MoH}$ Institutional Review Board Central Committee (Approval number 20-75 M). Data privacy and confidentiality were maintained throughout the study as subjects were labeled with unique identification numbers; data concealment was maintained throughout the study by generating strong passwords for the electronic system and limiting access to designated investigators after signing nondisclosure agreement forms.

Descriptive statistics were used to describe categorical variables that were presented by counts and percentages. In contrast, continuous variables were based on the median and interquartile range (IQR) since the normality test was significant using the Kolmogorov-Smirnov test and the Shapiro-Wilk test. The non-parametric Mann Whitney U-test was used to compare two numerical groups. Categorical variables underwent a test of association using the Chi-square test or Fisher exact test when the number of cases was small.

Univariable and multivariable logistic regression models were used to obtain the crude and the adjusted odds ratio (OR) and their associated $95 \%$ confidence interval (CI). All percentages were rounded to one decimal place. The statistical significance was set to a $P$-value of $<$ 0.05. The analysis was done using Statistical Package for the Social Sciences 24 (IBM-SPSS-24).

\section{Results}

Between 1-31 March 2020 a total of 1519 COVID-19-posf itive cases were screened, 648 patients with definitive outcomes were included in the analysis; $11.9 \%(n=77)$ of them were critical while $88.1 \%(n=571)$ were non-critical (Figure 1). Out of the 77 critical patients, $15.6 \%(n=12)$ patients have died and $84.4 \%(n=65)$ have recovered (Figure 1). The distribution of gender varied between critical and non-critical groups where males constituted $67.5 \%(n=52)$ of the critical group versus $50.8 \%(n=290)$ of the non-critical group, with a statistically significant association $P=0.006$. The median and IQR of age differed significantly $P=0.001$ across critical cases vera sus non-critical cases with 37 years (27) and 33 years (18), respectively. Smoking was not associated with the worse outcomes, with a P-value of 0.943 (Table 1). Additionally, the extracted outcomes were presented by age and gender (Figure 2).

Comorbidities were seen in a high percentage of cases where $29 \%(n=188$ of 648$)$ had one or more. Comorbidities were higher in the critical group with $42.9 \%$ ( $n=33)$ having one or more comorbidity, and $27.3 \%(n=21)$ having two or more comorbidities. On the other side, $27.1 \%(n=155)$ of the non-critical patients had one or more comorbidity, and $10 \%(n=57)$ had two or more comorbidities. The association between the presence of one or more comorbidity was significantly associated with outcomes with $P=0.004$. The comorbidities included diabetes mellitus (DM), hypertension (HTN), cardiac diseases, chronic respiratory diseases (CRD), cancer, immunodeficiency, and chronic kidney diseases (CKD).

Diabetes was seen in $11.3 \%$ ( $n=73$ of 648$)$ of the cases with $20.8 \%(n=16)$ in the critical arm versus $10 \%(n=57)$ in the non-critical arm $(P=0.005)$. Cardiac and cancer/ immunodeficient patients were $3.5 \%(n=23$ of 648$)$ and $2.8 \%(n=18$ of 648$)$ of the cases, respectively. Cardiac patients were present in $10.4 \%(n=8)$ of the critical group versus $2.6 \%(n=15)$ in the non-critical group $P=0.001$. Similarly, cancer and immunodeficiency were seen in $6.5 \%(n=5)$ of the critical arm versus $2.3 \%(n=13)$ in the non-critical arm. Among cases, CRD was reported in $12.5 \%(n=81$ of 648$)$ of the population with $22.1 \%(n=17)$ in the critical patients arm versus $11.2 \%(n=64)$ in the non- 


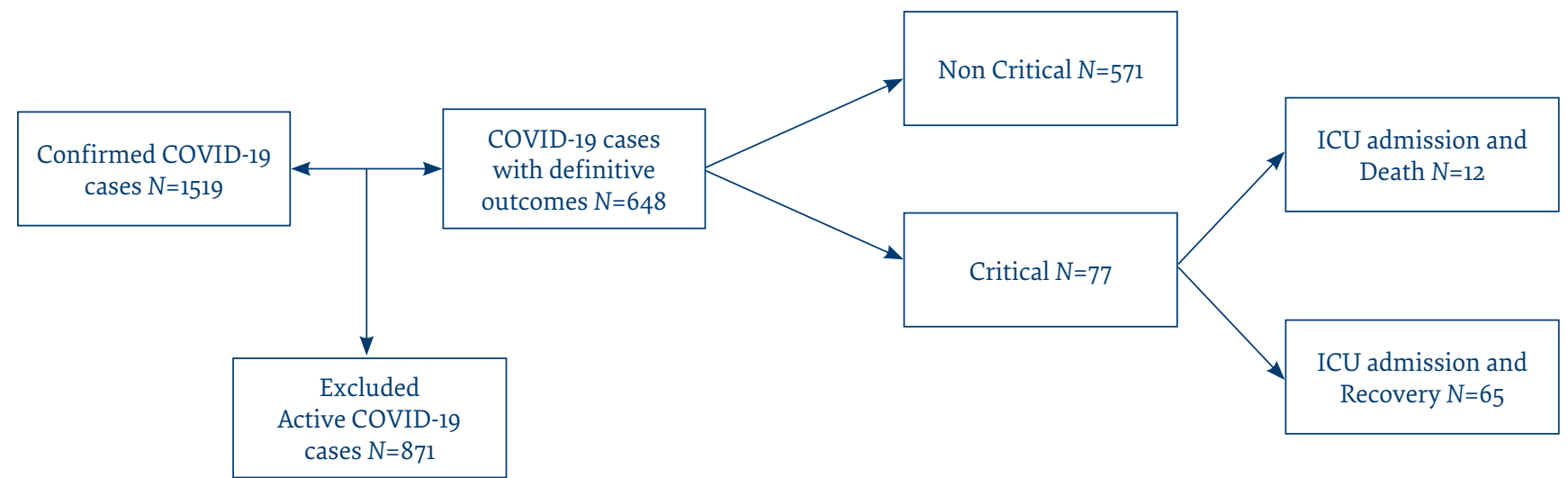

critical arm with statistically significant differences $P=0.007$ (Table 1).

Fever was seen in $85.3 \%$ ( $n=163$ of 191 ), with a slightly higher percentage $94.7 \%$ in the critical group $(n=36)$ versus $83 \%(n=127)$ in the non-critical group. However, there was no statistical difference across the two groups. Cough was reported in $89 \%(n=203$ of 228$)$ of the total group with a significant difference across the two groups outcomes $P=0.049$. Sore throat, runny nose, and headache were reported in $79.3 \%$ ( $n=115$ of 145$), 74.5 \%$ ( $n=73$ of 98 ) and $27.8 \%$ ( $n=140$ of 503$)$ respectively. None of those symptoms showed significant differences across critical and non-critical arms. Gastrointestinal (GI) symptoms and myalgia were reported by $14.1 \%(n=71$ of 503$)$ and $28.8 \%$ ( $n=145$ of 503 ), respectively. In addition, there were no statistical differences observed across the two arms outcomes (Table 1).

Vital signs were evaluated for the population based on their continuous scale or predefined categories. However, for vital signs and laboratory results, there were missing data for a high number of cases. There was no statistical difference in both continuous and categorical presentation where heart rate $\geq 100$ beats per minute occurred in $36.8 \%(n=7)$ of the critical group versus $20.8 \%$ $(n=20)$ of the non-critical group. Similarly, the respiratory rate had a median (IQR) of 20 (2) breaths per minute. The cut-off for the categories was taken as 24 breaths per minute. No significant difference occurred in the groups' outcomes. Oxygen saturation had a median (IQR) of 98 (3) $\%$ with a cut-off value of $94 \%$. The comparison across the two groups outcomes yielded no significant differences either. Finally, systolic and diastolic blood pressures had a median (IQR) of 125 (22) $\mathrm{mmHg}$ and 74 (12) $\mathrm{mmHg}$, respectively, with no significant differences in the critical versus non-critical groups (Table 1). Neutrophils as well as WBC total count and lymphocytes percentages had no statistically significant differences across the groups of these variables (Table 1).
The overall in-hospital length of stay (LOS) in days had a median (IQR) of 5 (14) days. There was a significant difference in the LOS $P=0.001$ as critical patients had longer LOS with a median (IQR) of 11.5 (11) days versus 4 (12) days for non-critical cases (Table 1). The LOS was illustrated for different risk groups (Figure 3). Older patients (age 265 ), diabetic, hypertensive, CKD, and cancer patients/immunodeficient had a longer median LOS of 10 days. Patients without comorbidities had the lowest median LOS with only two days (Figure 3).

Several risk factors were explored using logistic regression with outcomes being binary as critical or noncritical. Crude and adjusted ORs were calculated using age as a continuous variable and gender (Table 2). Male gender was found to be a statistically significant risk factor $P=0.012$ with a crude OR and 95\% CI of 2.01 (1.223.34). The OR of male gender became $1.92(1.15-3.20)$ after adjusting for age. Older age was found to be significant on the continuous and categorical scales. Those with an age of $\geq 65$ years had 3.15 (1.40-7.09) higher odds ratios of experiencing ICU admission or death with significant $P=0.007$. Moreover, age categories showed an increasing trend of being in the critical group where the age group 41-60 years had an OR=1.90 (0.69-5.25) and those $>60$ years had $\mathrm{OR}=4.04(1.32-12.36)$ against the $1-20$ years reference group.

Being a smoker had an OR=0.98 (0.51-1.88) with a nonsignificant $P$-value that remained non-significant even after adjusting for age and sex. Comorbidities showed significantly increased odds of being in the critical group with one or more comorbidity having $\mathrm{OR}=2.01 \quad\left(1.24^{-}\right.$ 3.28), two or more comorbidities had OR=3.38 (1.91-5.99), DM 2.37 (1.28-4.37), and HTN 2.28 (1.23-4.20). These comorbidities had their adjusted OR decreased indicating that the age and gender are potential confounders.

Patients with CKD had an $\mathrm{OR}=1.50(0.32-6.96)$ that remained non-significant when adjusted for age and sex. On the other hand, CRD was considered to be a significant risk factor with an adjusted $\mathrm{OR}=2.29\left(1.24^{-}\right.$ 
Table 1 Baseline characteristics of the COVID-19 cases based on their reported outcomes

\begin{tabular}{|c|c|c|c|c|}
\hline Characteristic & $\begin{array}{l}\text { Total Patients } \\
(\mathrm{N}=\mathbf{6 4 8})\end{array}$ & $\begin{array}{r}\text { Critical } \\
(\mathrm{N}=77)\end{array}$ & $\begin{array}{c}\text { Non-critical } \\
(\mathrm{N}=571)\end{array}$ & P-value* \\
\hline Sex* & & & & 0.006 \\
\hline Male & $342(52.8 \%)$ & $52(67.5 \%)$ & $290(50.8 \%)$ & \\
\hline Female & $306(47.2 \%)$ & $25(32.5 \%)$ & $281(49.2 \%)$ & \\
\hline Age* $^{*}(M D, I Q R)$-years & $34(19)$ & $37(27)$ & $33(18)$ & 0.001 \\
\hline Age $^{*}$ Categories -years & & & & 0.001 \\
\hline $1-20$ & $69(10.6 \%)$ & $5(6.5 \%)$ & $64(11.2 \%)$ & \\
\hline $21-40$ & $359(55.4 \%)$ & $38(49.4 \%)$ & $321(56.2 \%)$ & \\
\hline $41-60$ & $170(26.2 \%)$ & $22(28.6 \%)$ & $148(25.9 \%)$ & \\
\hline$>60$ & $50(7.7 \%)$ & $12(15.6 \%)$ & $38(6.7 \%)$ & \\
\hline Age $e^{*}$ (binary) -years & & & & 0.001 \\
\hline$<65$ & $616(95.1 \%)$ & $68(88.3 \%)$ & $548(96.0 \%)$ & \\
\hline$\geq 65$ & $32(4.9 \%)$ & $9(11.7 \%)$ & $23(4.0 \%)$ & \\
\hline Smoking Status (N=647) & & & & 0.943 \\
\hline Yes & $104(16.1 \%)$ & $12(15.8 \%)$ & $92(16.1 \%)$ & \\
\hline No & $543(83.9 \%)$ & $64(84.2 \%)$ & $479(83.9 \%)$ & \\
\hline Occupation & & & & 0.443 \\
\hline Working in health care facilities ${ }^{*}$ & $101(15.6 \%)$ & $14(18.2 \%)$ & $87(15.2 \%)$ & \\
\hline Military & $21(3.2 \%)$ & $4(5.2 \%)$ & $17(3.0 \%)$ & \\
\hline Others & $526(81.2 \%)$ & $59(76.6 \%)$ & $467(81.8 \%)$ & \\
\hline \multicolumn{5}{|l|}{ Comorbidities } \\
\hline Diabetes Mellitus* & $73(11.3 \%)$ & $16(20.8 \%)$ & $57(10.0 \%)$ & 0.005 \\
\hline Hypertension* & $75(11.6 \%)$ & $16(20.8 \%)$ & $59(10.3 \%)$ & 0.007 \\
\hline Chronic kidney disease & $12(1.9 \%)$ & $2(2.6 \%)$ & $10(1.8 \%)$ & 0.605 \\
\hline Chronic respiratory diseases ${ }^{*} \ddagger$ & $81(12.5 \%)$ & $17(22.1 \%)$ & $64(11.2 \%)$ & 0.007 \\
\hline Cancer/Immunodeficiency* & $18(2.8 \%)$ & $5(6.5 \%)$ & $13(2.3 \%)$ & 0.035 \\
\hline Cardiac diseases ${ }^{*} \dagger$ & $23(3.5 \%)$ & $8(10.4 \%)$ & $15(2.6 \%)$ & 0.001 \\
\hline No comorbidity & $382(59.0 \%)$ & $23(29.8 \%)$ & $359(62.9 \%)$ & 0.001 \\
\hline 1 or more Comorbidity* & $188(29.0 \%)$ & $33(42.9 \%)$ & $155(27.1 \%)$ & 0.004 \\
\hline 2 or more Comorbidity ${ }^{*}$ & $78(12.0 \%)$ & $21(27.3 \%)$ & $57(10.0 \%)$ & 0.001 \\
\hline Length of stay* (MD, IQR) -days & $5(14)$ & $11.5(11)$ & $4(12)$ & 0.001 \\
\hline \multicolumn{5}{|l|}{ Symptoms } \\
\hline Fever $(N=191)$ & $163(85.3 \%)$ & $36(94.7 \%)$ & $127(83.0 \%)$ & 0.067 \\
\hline Cough $^{*}(N=228)$ & $203(89.0 \%)$ & $41(97.6 \%)$ & $162(87.1 \%)$ & 0.049 \\
\hline Sore Throat $(N=145)$ & $115(79.3 \%)$ & $18(85.7 \%)$ & $97(78.2 \%)$ & 0.433 \\
\hline Runny Nose $(N=98)$ & $73(74.5 \%)$ & $7(63.6 \%)$ & $66(75.9 \%)$ & 0.381 \\
\hline Headache $(N=504)$ & $140(27.8 \%)$ & $10(18.2 \%)$ & $130(29.0 \%)$ & 0.092 \\
\hline GI Symptoms $\neq(N=504)$ & $71(14.1 \%)$ & $11(20.0 \%)$ & $60(13.4 \%)$ & 0.182 \\
\hline Myalgia $(N=504)$ & $145(28.8 \%)$ & $17(30.9 \%)$ & $128(28.5 \%)$ & 0.710 \\
\hline \multicolumn{5}{|l|}{ Vital Signs } \\
\hline Temperature $(N=268)$ - $C$ & & & & 0.132 \\
\hline$<38$ & $219(81.7 \%)$ & $34(73.9 \%)$ & $185(83.3 \%)$ & \\
\hline$\geq 38$ & $49(18.3 \%)$ & $12(26.1 \%)$ & $37(16.7 \%)$ & \\
\hline Heart rate $(\mathrm{N}=115)$-beats/min & & & & 0.133 \\
\hline$<100$ & $88(76.5 \%)$ & $12(63.2 \%)$ & $76(79.2 \%)$ & \\
\hline$\geq 100$ & $27(23.5 \%)$ & $7(36.8 \%)$ & $20(20.8 \%)$ & \\
\hline Respiratory rate (MD, IQR) - breaths/min & $20(2.0)$ & $20(4.0)$ & $20(2.0)$ & 0.260 \\
\hline Respiratory rate $(\mathrm{N}=106)$ & & & & 0.187 \\
\hline$\leq 24$ & $101(95.3 \%)$ & $17(89.5 \%)$ & $84(96.6 \%)$ & \\
\hline$>24$ & $5(4.7 \%)$ & $2(10.5 \%)$ & $3(3.4 \%)$ & \\
\hline
\end{tabular}


Table 1 Baseline characteristics of the COVID-19 cases based on their reported outcomes (concluded)

\begin{tabular}{|c|c|c|c|c|}
\hline Characteristic & $\begin{array}{l}\text { Total Patients } \\
\quad(\mathrm{N}=648)\end{array}$ & $\begin{array}{c}\text { Critical } \\
(\mathbf{N}=77)\end{array}$ & $\begin{array}{c}\text { Non-critical } \\
(\mathrm{N}=571)\end{array}$ & P-value* \\
\hline SBP (MD, IQR) - $\mathrm{mmHg}$ & $125(22.0)$ & $121(20.0)$ & $125(21.0)$ & 0.336 \\
\hline $\mathrm{DBP}(\mathrm{MD}, \mathrm{IQR})-\mathrm{mmHg}$ & $74(12.0)$ & $74(10.0)$ & $74.5(14.0)$ & 0.450 \\
\hline Oxygen saturation (MD, IQR) -\% & $98(3.0)$ & $98(3.3)$ & $98(3.0)$ & 0.659 \\
\hline Oxygen saturation $(N=259)$ & & & & 0.610 \\
\hline$<94$ & $28(10.8 \%)$ & $4(8.7 \%)$ & $24(11.3 \%)$ & \\
\hline$\geq 94$ & $231(89.2 \%)$ & $42(91.3 \%)$ & $189(88.7 \%)$ & \\
\hline \multicolumn{5}{|l|}{ Blood Laboratory testing } \\
\hline WBC means (MD, IQR) $-10^{3} / \mu \mathrm{L}$ & $5.5(3.3)$ & $6.5(7.8)$ & $5.5(3.0)$ & 0.460 \\
\hline$W B C(N=34)$ & & & & 0.906 \\
\hline$<4$ & $5(14.7 \%)$ & $1(12.5 \%)$ & $4(15 \cdot 4 \%)$ & \\
\hline 4-12 & $26(76.5 \%)$ & $6(75.0 \%)$ & $20(76.9 \%)$ & \\
\hline$>12$ & $3(8.8 \%)$ & $1(12.5 \%)$ & $2(7.7 \%)$ & \\
\hline Neutrophils (MD, IQR) -\% & $62.1(67.9)$ & $68(47.3)$ & $60.2(67.3)$ & 0.405 \\
\hline Neutrophils $(\mathrm{N}=28)$ & & & & 0.777 \\
\hline$<55$ & $10(35.7 \%)$ & $2(28.6 \%)$ & $8(38.1 \%)$ & \\
\hline $55-70$ & $9(32.1 \%)$ & $2(28.6 \%)$ & $7(33.3 \%)$ & \\
\hline$>70$ & $9(32.1 \%)$ & $3(42.9 \%)$ & $6(28.6 \%)$ & \\
\hline Lymphocytes (MD, IQR) -\% & $21.8(13.7)$ & $22.4(31.2)$ & $21.8(13.0)$ & 0.919 \\
\hline Lymphocytes $(\mathrm{N}=23)$ & & & & 0.923 \\
\hline$<20$ & $10(43.5 \%)$ & $3(50.0 \%)$ & $7(41.2 \%)$ & \\
\hline $20-40$ & $10(43.5 \%)$ & $2(33.3 \%)$ & $8(47.1 \%)$ & \\
\hline$>40$ & $3(13.0 \%)$ & $1(16.7 \%)$ & $2(11.8 \%)$ & \\
\hline
\end{tabular}

$\mathrm{MD}=$ median; $\mathrm{IQR}=$ interquartile range; $\mathrm{GI}=$ gastrointestinal; $\mathrm{SBP}=$ systolic blood pressure; $\mathrm{DBP}=$ diastolic blood pressure; $\mathrm{WBC}=$ white blood cells

* Significant result at $a=0.05$

$\times$ Involves physicians, nurses, pharmacists, lab technicians, cleaners, and other workers in health care facilities

$\ddagger$ Includes asthma, COPD, interstitial lung disease, bronchiectasis, lung cancer, and others

$\dagger$ Includes Ischemic heart diseases and heart failure

$\neq$ Involves abdominal pain, vomiting, or diarrhoea

4.25). Cancer/immunodeficient patients had a significant crude $\mathrm{OR}=2.98$ (1.03-8.61) that became non-significant when adjusted with $\mathrm{OR}=2.24(0.73-6.87)$. Finally, cardiac patients showed the highest $\mathrm{OR}=4.30(1.76-10.50)$ that remained significant even after adjusting for age and sex with an $\mathrm{OR}=3.05$ (1.16-8.02). None of the symptoms showed a significant association with the outcomes even after adjusting for age and sex (Table 2).

\section{Discussion}

To the best of our knowledge, this is one of the first studies in the Eastern Mediterranean Region to assess the association between common comorbidities, clinical manifestations and laboratory results for critical COVID-19 patients. We found an association between gender, age, diabetes, HTN, chronic respiratory diseases, cardiac diseases, cancer patients/immunodeficiency with the outcomes of clinical interest. There was no significant association among tobacco smokers or patients presenting with specific signs and symptoms.

The gender distribution of our patients was 53\% males and $47 \%$ females. In addition, males were seen more in the critical group $67.5 \%$ versus $32.5 \%$ in females. These findings are consistent with previous evidence that suggests male patients have a higher severity and mortality $(6,16)$.

The median age of our sample was 34 years; this could be attributed to the young population of Saudi Arabia (17). When age was analyzed as a continuous variable, it showed a significant association with increased risk by almost $3 \%$ each year. Consistent with the literature, cases aged 65 years or older had an increased risk of being admitted to ICU or dying from COVID-19 $(18,19)$. The results were also significant in patients older than 60 years of age with an increase in risk by 3.65 times (95\% CI: $1.18-11.27$ ) in relation to those $1-20$ years-old cases. Remarkably, $15.6 \%$ of the critical cases were over the age of 60 . These findings confirmed the previous evidence reporting age as a risk factor for poor outcomes $(5,20)$. However, with a lower cutoff age of 60 years when compared with recent studies $(2,18)$. This might be related to comorbidities appearing at an early age in our population (21). Age-related responses with weak immune systems are probable contributing factors for adverse outcomes of the disease (18). 
Figure 2 Age and gender distribution per outcomes in 648 laboratory-confirmed COVID-19 cases with definitive outcomes in Saudi Arabia, 1-31 March, 2020

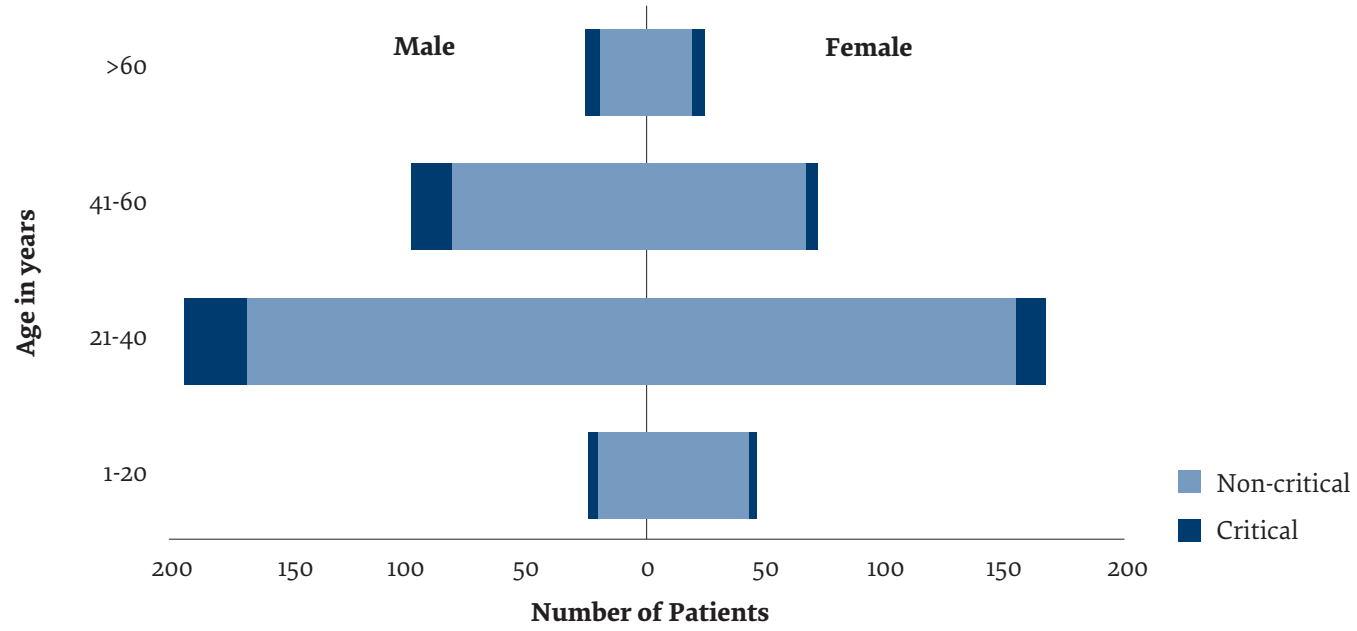

Both DM and HTN were associated with worse outcomes with a crude OR around 2.37 and 2.28, respectively. This is supported by previous cohort studies confirming similar findings $(5,6)$. However, the adjusted OR became non-significant $(P=0.304, P=0.443$ for DM and HTN, respectively), which may indicate that the crude OR was biased. On the other hand, patients with a history of cardiac diseases had significantly higher adjusted OR, strongly suggesting that cardiac diseases were an independent risk factor for ICU admission and mortality. This concurs with findings reported by previous studies that cardiac diseases were associated with worse outcomes among COVID-19 patients $(5,6)$. The impact of cardiovascular diseases in COVID-19 could be related to the impaired cardiovascular compensatory mechanism or the direct cardiac injury reported to be associated with a higher incidence of worse outcomes (22). Furthermore, a study conducted in Wuhan, China, found cardiac injuries in almost $20 \%$ of their COVID-19 patients and more frequent in cardiac patients with higher mortality (23). In our study, CRD was a significant factor for ICU admission and mortality as adjusted with an OR of 2.29 (CI: $1.24-4.25$ ) and $P=0.008$. This was supported by similar findings from a recent observational

Figure 3 Median length of in-hospital stay (LOS) for a total of 648 COVID-19 patients according to different risk factors and outcomes

According to Risk Factors

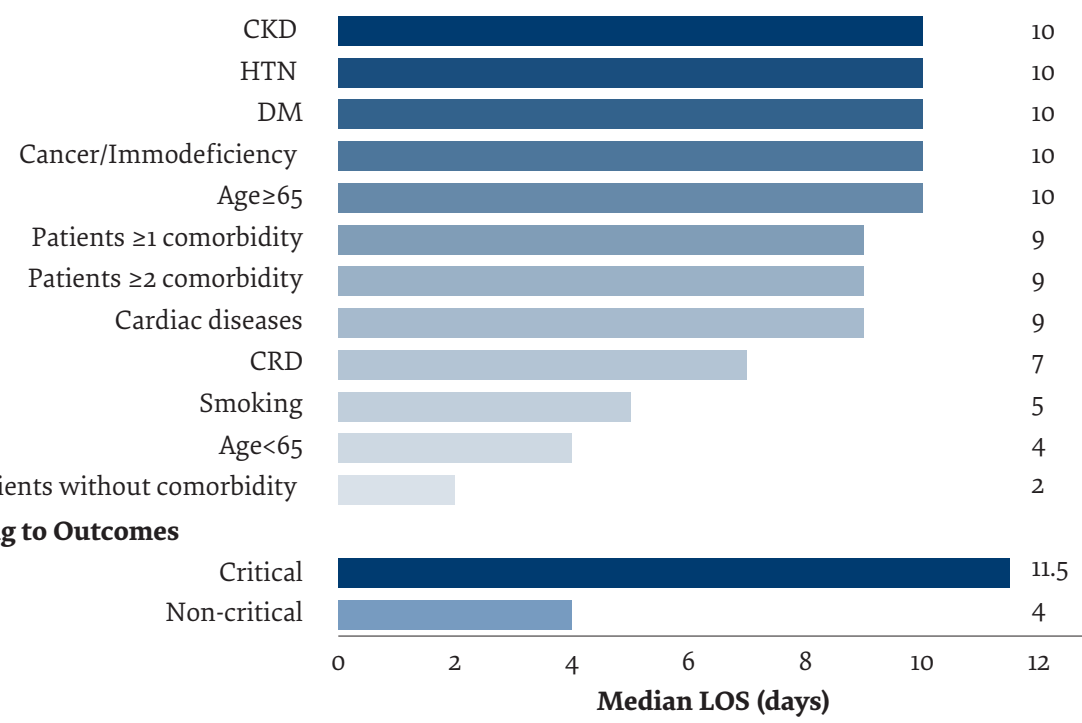




\begin{tabular}{|c|c|c|c|c|}
\hline & Crude OR (95\% CI) & P-value & Adjusted OR* (95\%CI) & P-value \\
\hline Sex (Male) & $2.01(1.22-3.34)$ & 0.006 & $1.92(1.15-3.20)$ & 0.012 \\
\hline Age (continuous) -years & $1.03(1.01-1.05)$ & 0.001 & $1.03(1.01-1.04)$ & 0.001 \\
\hline Age $(\geq 65)$ - years & $3.15(1.40-7.09)$ & 0.005 & $3.07(1.35-6.96)$ & 0.007 \\
\hline \multicolumn{5}{|l|}{ Age Categories - years } \\
\hline $1-20$ & Reference & - & Reference & \\
\hline $21-40$ & $1.52(0.57-3.99)$ & 0.401 & $1.33(0.50-3.55)$ & 0.564 \\
\hline $41-60$ & $1.90(0.69-5.25)$ & 0.214 & $1.63(0.59-4.54)$ & 0.35 \\
\hline$>60$ & $4.04(1.32-12.36)$ & 0.014 & $3.65(1.18-11.27)$ & 0.024 \\
\hline Smoker & $0.98(0.51-1.88)$ & 0.943 & $0.79(0.40-1.58)$ & 0.517 \\
\hline \multicolumn{5}{|l|}{ Comorbidities } \\
\hline One or more comorbidity & $2.01(1.24-3.28)$ & 0.005 & $1.51(0.87-2.62)$ & 0.141 \\
\hline Two or more Comorbidity & $3.38(1.91-5.99)$ & 0.001 & $2.57(1.33-4.97)$ & 0.005 \\
\hline Diabetes Mellitus & $2.37(1.28-4.37)$ & 0.006 & $1.45(0.72-2.93)$ & 0.304 \\
\hline Hypertension & $2.28(1.23-4.20)$ & 0.009 & $1.37(0.64-2.80)$ & 0.443 \\
\hline CRD & $2.25(1.23-4.08)$ & 0.008 & $2.29(1.24-4.25)$ & 0.008 \\
\hline Chronic Kidney diseases & $1.50(0.32-6.96)$ & 0.608 & $0.98(0.21-4.68)$ & 0.981 \\
\hline Cardiac Diseases & $4.30(1.76-10.50)$ & 0.001 & $3.05(1.16-8.02)$ & 0.024 \\
\hline Cancer/Immunodeficiency & $2.98(1.03-8.61)$ & 0.043 & $2.24(0.73-6.87)$ & 0.158 \\
\hline \multicolumn{5}{|l|}{ Symptoms } \\
\hline Fever & $3.69(0.84-16.27)$ & 0.085 & $2.78(0.61-12.59)$ & 0.185 \\
\hline Cough & $6.07(0.79-46.23)$ & 0.081 & $5.05(0.65-39.02)$ & 0.121 \\
\hline Sore Throat & $1.67(0.46-6.09)$ & 0.437 & $1.28(0.34-4.88)$ & 0.715 \\
\hline Runny Nose & $0.56(0.15-2.09)$ & 0.386 & $0.50(0.13-1.94)$ & 0.317 \\
\hline Headache & $0.55(0.27-1.12)$ & 0.096 & $0.62(0.30-1.28)$ & 0.199 \\
\hline GI Symptoms & $1.62(0.79-3.31)$ & 0.185 & $1.80(0.87-3.74)$ & 0.113 \\
\hline Myalgia & $1.12(0.61-2.06)$ & 0.711 & $1.18(0.63-2.18)$ & 0.610 \\
\hline \multicolumn{5}{|l|}{ Vital Signs } \\
\hline Temperature $(\geq 38)$ - & $1.77(0.84-3.72)$ & 0.136 & $1.64(0.77-3.51)$ & 0.200 \\
\hline Heart Rate $\geq 100$-beats/min & $2.22(0.77-6.36)$ & 0.139 & $1.99(0.67-5.88)$ & 0.216 \\
\hline Respiratory Rate (Continuous) -breaths/min & $1.13(0.93-1.36)$ & 0.212 & $1.10(0.91-1.33)$ & 0.307 \\
\hline Respiratory rate (>24) & $3.29(0.51-21.24)$ & 0.210 & $2.34(0.35-15.84)$ & 0.384 \\
\hline SBP (continuous) - $\mathrm{mmHg}$ & $0.99(0.96-1.02)$ & 0.595 & $0.99(0.96-1.02)$ & 0.365 \\
\hline DBP (continuous) - $\mathrm{mmHg}$ & $0.97(0.93-1.03)$ & 0.319 & $0.96(0.90-1.02)$ & 0.143 \\
\hline Oxygen saturation \% & $1.02(0.93-1.13)$ & 0.652 & $1.04(0.93-1.15)$ & 0.513 \\
\hline Oxygen saturation $(<94)$ & $0.75(0.25-2.28)$ & 0.611 & $0.75(0.24-2.33)$ & 0.623 \\
\hline
\end{tabular}

$O R=$ odd s ratio: $C I=$ confidence interval

$C R D=$ chronic respiratory diseases;

$G I=$ gastrointestinal; $S B P=$ systolic blood pressure;

$\mathrm{DBP}=$ diastolic blood pressure

${ }^{*}$ Adjusted for age and gender

study carried out in the UK indicating that CRD was a risk factor for in-hospital mortality in COVID-19 patients (6).

Having two or more comorbidities are independent risk factors for ICU admission and mortality with an adjusted $\mathrm{OR}=2.57$. Comorbidities should be considered when risk stratifying patients with COVID-19 as supported by the nationwide analysis from China (8). Although initial symptoms and vital signs were not associated with worse outcomes, it is crucial to not fully rely on the initial clinical manifestations in predicting outcomes for COVID-19 patients because the disease might have an unpredictable course.

The missing data variables in our study contributed broadly to these differences in that we retrieved only 5.2\% of WBCs, $4.3 \%$ of neutrophils, and $3.5 \%$ of lymphocytes results; these failed to generate a robust analysis to assess the association.

Tobacco smoking is a controversial factor in COVID-19. There has been a strong relation between angiotensin-converting enzyme 2 (ACE2) expression in the lung tissue and the spread of COVID-19 disease. 
Smoking is remarkably associated with dose-dependent upregulation of ACE2 expression causing more harm in developing critical outcomes among the patients $(24,25)$. On the contrary, some reports have not found smoking to be associated with COVID-19 severity (26). Surprisingly, one paper proposed smoking to be a protective factor against COVID-19 in developing less serious infections and hypothesized the pathophysiological explanation could be related to the nicotine effect (27). Nevertheless, our result confirmed the poor association between smoking and worse outcomes encouraging more structured studies in that subject to provide conclusive evidence.

Remarkably, the median LOS was 11.5 days for critical COVID-19 patients with only four days for the non-critical arm. This was expected considering the severity of the disease and the associated comorbidity; patients without comorbidities had a span of two days while those with comorbidities had a span of nine days. A recent study in China reported a median LOS of 14.5 days for critical patients, higher than the LOS seen in our results. This could be explained by their higher median age of critical cases compared to our cases, 63 years versus 37 years respectively (14).

A better understanding of this disease is critical to reducing the impact of the pandemic. Many of our findings are concordant with reported risk factors for COVID-19 disease. In many ways, this study will help risk-stratify, prioritize the detection, and guide clinical management and disposition effectively based on their demographic data, clinical symptoms, and associated comorbidities. Furthermore, it will support decisionmakers to unify clinical guidelines and describe predictors for mortality of COVID-19 in the Eastern Mediterranean Region. Based on the current evidence of risk factors and predictors, we suggest designing a special multi-item scale system to prognosticate COVID-19 patients. We encourage designing a comprehensive assessment tool that contains clinical symptoms, risk factors, radiological features, and laboratory findings of COVID-19 patients to anticipate the clinical courses and guide future management. Although some of the essential risk factors associated with poor outcomes have been described in this study, further prospective studies in the region are recommended to investigate various radiological features and expected laboratory values as predictors of COVID-19 prognosis.

This study identified many risk factors associated with adverse outcomes in COVID-19 patients, but several limitations were present. First, due to the retrospective nature of this study, we could not eliminate missing variables especially, in the vital signs and laboratory results. Therefore, no data analysis or interpretation could be withdrawn from these variables. Second, radiological studies were not available in the HESN database. This would have an additive value in risk-stratifying patients based on their radiological abnormalities. Third, many laboratory results were not retrieved including renal function tests, liver function tests, D-dimer, coagulation profile, and troponin levels. These could guide clinical practice if correlated with COVID-19 disease severity and related outcomes.

\section{Conclusions}

In subjects with COVID-19, age, male gender, cardiac diseases, CRD, and having two or more comorbidities were independent risk factors for ICU admission and mortality. Although the young Saudi population has limited risk, we found that age more than 60 years was associated with worse outcomes. Finally, neither the initial sign and symptoms nor tobacco smoking were linked to adverse outcomes. Based on the current evidence of risk factors and predictors, we suggest designing a unique multi-item scale system to prognosticate COVID-19 patients.

\section{Acknowledgment}

We would like to acknowledge the contribution of all MoH staff, mainly the General Directorate of Statistics and Information Management, and Directorate General of Infectious Diseases.

Funding: None.

Competing interests: None declared.

\section{Facteurs de risque associés à une détérioration des résultats pour la COVID-19 : étude rétrospective en Arabie saoudite}

\section{Résumé}

Contexte : L'émergence rapide de la maladie à nouveau coronavirus 2019 (COVID-19) a entraîné l'infection de millions de patients et des centaines de milliers de décès dans le monde entier. La prestation des services de soins de santé est mise à mal en raison de l'augmentation massive du nombre de patients infectés pendant cette pandémie.

Objectifs : La présente étude visait à évaluer les facteurs de risque associés à un mauvais pronostic chez les patients atteints de COVID-19 en Arabie saoudite. 
Méthodes : Il s'agissait d'une étude de cohorte rétrospective multicentrique qui incluait tous les cas de COVID-19 confirmés en laboratoire, avec des résultats définitifs en Arabie saoudite en mars 2020. Les données démographiques, les antécédents cliniques, la comorbidité et les résultats ont été extraits de la base de données du National Health Electronic Surveillance Network. Nous avons utilisé des modèles de régression logistique pour calculer les odds ratios bruts et ajustés (OR) afin d'étudier les facteurs de risque pour les résultats critiques (admission en unité de soins intensifs ou décès) parmi les cas de COVID-19.

Résultats : Nous avons inclus 648 patients positifs pour la COVID-19, dont lâge médian était de 34 ans. Parmi eux, 11,9\% appartenaient au groupe critique. Les facteurs de risque associés aux pires résultats comprenaient l'appartenance au sexe masculin $(\mathrm{OR}=1,92)$, un âge supérieur à 60 ans $(\mathrm{OR}=3,65)$, les maladies cardiaques $(\mathrm{OR}=3,05)$, les maladies respiratoires chroniques $(\mathrm{OR}=2,29)$ et les cas présentant deux comorbidités ou plus $(\mathrm{OR}=2,57)$ après ajustement en fonction de l'âge et du sexe ; tous avaient des valeurs $p$ inférieures à 0,05 significatives.

Conclusions : Les facteurs de risque indépendants pour les résultats critiques parmi les cas de COVID-19 comprennent la vieillesse, l'appartenance au sexe masculin, les maladies cardiaques, les maladies respiratoires chroniques et la présence de deux comorbidités ou plus. Nous recommandons de mettre au point un système d'échelle unique multi-items pour pronostiquer les patients atteints de COVID-19.

$$
\text { أنس خوان، صقر الخطر المرتبطة بالنتائج السيئة لمرض كوفي يوفيد-19: دراسة بأثر رجعي في المملكة العربية السعودية }
$$

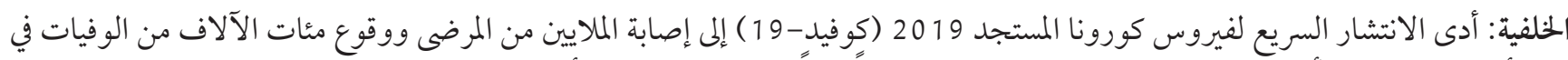

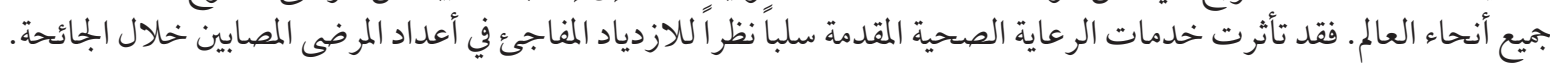

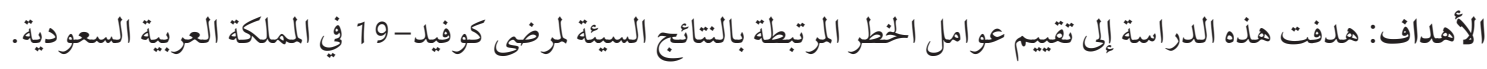

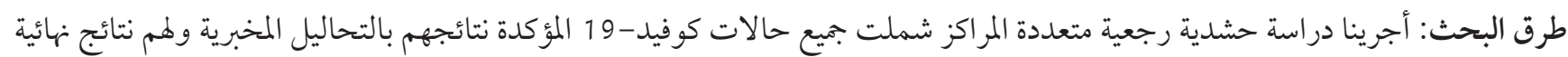

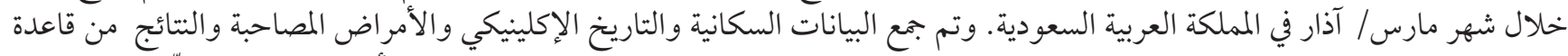

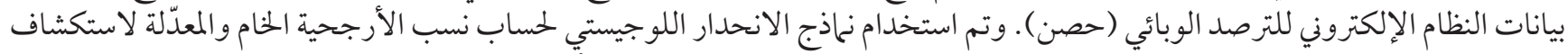

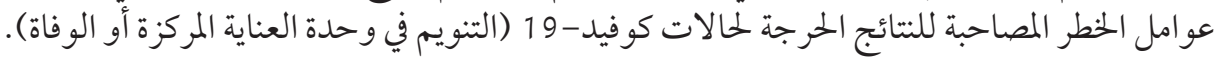

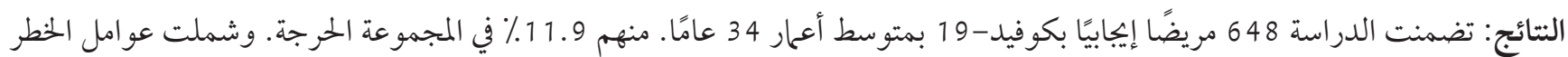

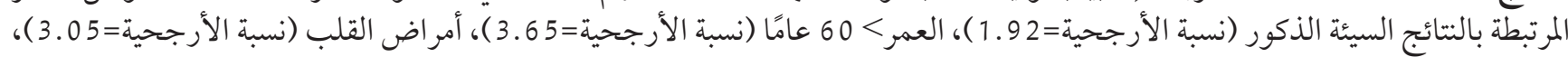

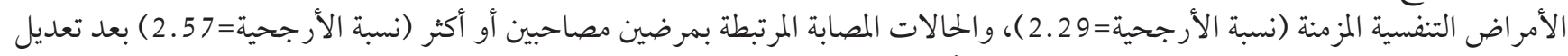

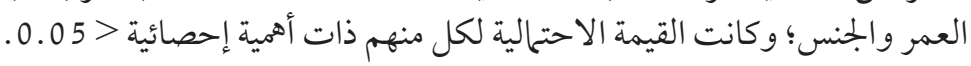

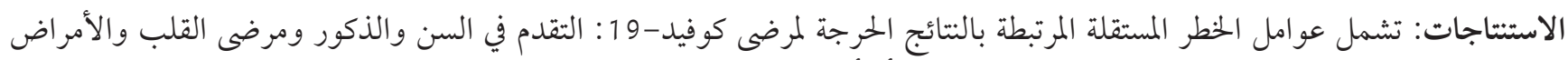

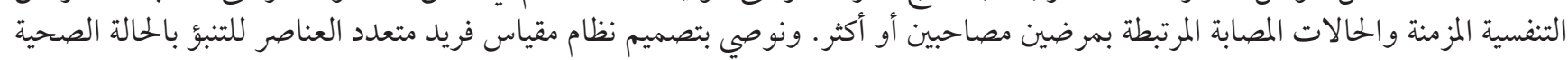
لمرضى كوفيد-19.

\section{References}

1. COVID-19 Daily Updates. Saudi Arabia. Riyadh: Ministry of Health; 2020 (https://covid19.moh.gov.sa/, accessed 14 June 2020).

2. Huang C, Wang Y, Li X, Ren L, Zhao J, Hu Y, et al. Clinical features of patients infected with 2019 novel coronavirus in Wuhan, China. The Lancet. 2020;395(10223):497-506. https://doi.org/10.1016/So140-6736 (20)30183-5.

3. Chen N, Zhou M, Dong X, Qu J, Gong F, Han Y, et al. Epidemiological and clinical characteristics of 99 cases of 2019 novel coronavirus pneumonia in Wuhan, China: a descriptive study. The Lancet. 2020;395(10223):507-513. https://doi.org/10.1016/So140-6736 (20)30211-7.

4. Wang D, Hu B, Hu C, Zhu F, Liu X, Zhang J, et al. Clinical characteristics of 138 hospitalized patients with 2019 novel coronavirus-infected pneumonia in Wuhan, China. JAMA. 2020;323(11):1061-1069. https://doi:10.1001/jama.2020.1585.

5. Zhou F, Yu T, Du R, Fan G, Liu Y, Liu Z, et al. Clinical course and risk factors for mortality of adult inpatients with COVID-19 in Wuhan, China: a retrospective cohort study. The Lancet. 2020;395 (10229):1054-1062. https://doi.org/10.1016/S0140-6736 (20)30566-3.

6. Docherty AB, Harrison EM, Green CA, Hardwick HE, Pius R, Norman L, et al. Features of 20133 UK patients in hospital with COVID-19 using the ISARIC WHO clinical characterization protocol: prospective observational cohort study. BMJ. 2020 May 22;369:m1985. https://doi.org/10.1136/bmj.m1985. 
7. Wu Z, McGoogan J. characteristics of and important lessons from the coronavirus disease 2019 (COVID-19) Outbreak in China. JAMA. 2020;323 (13):1239-1242. https://doi:10.1001/jama.2020.2648.

8. Guan W, Liang W, Zhao Y, Liang H, Chen Z, Li Y, et al. Comorbidity and its impact on 1590 patients with Covid-19 in China: A nationwide analysis. Eur Respir J. 2020;55 (6):2000547. https://doi.org/10.1183/13993003.00547-2020.

9. Alsofayan Y, Althunayyan S, Khan A, Hakawi A, Assiri A. Clinical characteristic of COVID-19 in Saudi Arabia: A national retrospective study. J Infect Public Health. 2020;13(7):920-925.https://doi.org/10.1016/j.jiph.2020.05.026.

10. National laboratories. Geneva: World Health Organization; 2020 (https://www.who.int/emergencies/diseases/novel-coronavin rus-2019/technical-guidance/laboratory-guidance/, accessed 8 June 2020).

11. Risk stratification for severe disease in patients with coronavirus disease 2019 (COVID-19). UpToDate; 2020 https://www.uptoo date.com/contents/image/print?imageKey=PWYS\%2F127891\&topicKey=PC\%2F127759\&search=covid\&source=outline_link\&selectedTitle $=5 \sim 150$, accessed 1 June 2020).

12. Singer M, Deutschman C, Seymour C, Shankar-Hari M, Annane D, Bauer M, et al. The Third International Consensus Definitions for Sepsis and Septic Shock (Sepsis-3). JAMA. 2016;315 (8):801-810. https://doi:10.1001/jama.2016.0287.

13. ICD-10 for Mortality and Morbidity Statistics. Geneva: World Health Organization; 2019 (https://icd.who.int/browse10/2019/en, accessed 24 May 2020).

14. Guan W, Ni Z, Hu Y, Liang W, Ou C, He J, et al. Clinical characteristics of coronavirus disease 2019 in China. New Engl J Med. 2020;382 (18):1708-1720. https://doi:10.1056/NEJMoa2002032.

15. COVID-19 coronavirus disease guidelines. Riyadh: Ministry of Health; 2020 (https://www.moh.gov.sa/Ministry/MediaCenter/ Publications/Documents/Coronavirus-Disease-2019-Guidelines-v1.2.pdf, accessed 28 May 2020).

16. Chen T, Wu D, Chen H, Yan W, Yang D, Chen G, et al. Clinical characteristics of 113 deceased patients with coronavirus disease 2019: retrospective study. BMJ. 2020;368:m1091. https://doi.org/10.1136/bmj.m1091.

17. Population by gender, age groups and nationality (Saudi/Non-Saudi). Riyadh: General Authority for Statistics; 2018 (https:// www.stats.gov.sa/en/5680/, accessed 27 May 2020).

18. Wu C, Chen X, Cai Y, Xia J, Zhou X, Xu S, et al. Risk factors associated with acute respiratory distress syndrome and death in patients with coronavirus disease 2019 pneumonia in Wuhan, China. JAMA Intern Med. 2020;180(7):934-943. https://doi. org/10.1001/jamainternmed.2020.0994.

19. Yang X, Yu Y, Xu J, Shu H, Xia J, Liu H, et al. Clinical course and outcomes of critically ill patients with SARS-CoV-2 pneumonia in Wuhan, China: a single-centered, retrospective, observational study. Lancet Respir Med. 2020 May;8(5):475-481. https:// doi:10.1016/S2213-2600 (20)30079-5.

20. Grasselli G, Zangrillo A, Zanella A, Antonelli M, Cabrini L, Castelli A, et al. Baseline characteristics and outcomes of 1591 patients infected with SARS-CoV-2 admitted to ICUs of the Lombardy region, Italy. JAMA. 2020;323 (16):1574-1581. https://doi:10.1001/ jama.2020.5394.

21. Khoja AT, Aljawadi MH, Al-Shammari SA, Mohamed AG, Al-Manaa HA, Morlock L, et al. The health of Saudi older adults; results from the Saudi National Survey for elderly health (SNSEH) 2006-2015. Saudi Pharm J. 2018 Feb 1;26(2):292-300. https://doi. org/10.1016/j.jsps.2017.11.008.

22. Li B, Yang J, Zhao F, Zhi L, Wang X, Liu L, et al. Prevalence and impact of cardiovascular metabolic diseases on COVID-19 in China. Clin Res Cardiol. 2020;531-538. https://doi.org/10.1007/s00392-020-01626-9.

23. Shi S, Qin M, Shen B, Cai Y, Liu T, Yang F, et al. Association of cardiac injury with mortality in hospitalized patients with COVID-19 in Wuhan, China. JAMA Cardiol. 2020;5(7):802-810. https://doi:10.1001/jamacardio.2020.0950.

24. Smith JC, Sausville EL, Girish V, Yuan ML, Vasudevan A, John KM, et al. Cigarette smoke exposure and inflammatory signaling increase the expression of the SARS-CoV-2 receptor ACE2 in the respiratory tract. Dev Cell. 2020 May 16;53(5):514-529.e3. https:// doi.org/10.1016/j.devcel.2020.05.012.

25. Zheng Z, Peng F, Xu B, Zhao J, Liu H, Peng J, et al. Risk factors of critical \& mortal COVID-19 cases: A systematic literature review and meta-analysis. J Infect. 2020 Aug;81(2):e16-e25 Epub 2020 https://doi.org/10.1016/j.jinf.2020.04.021.

26. Lippi G, Henry BM. Active smoking is not associated with severity of coronavirus disease 2019 (COVID-19). Eur J Intern Med. 2020 May;75:107-108. https://doi:10.1016/j.ejim.2020.03.014.

27. Miyara M, Tubach F, Pourcher V, Morelot-Panzini C, Pernet J, Haroche J, et al. Low rate of daily active tobacco smoking in patients with symptomatic COVID-19. Qeios. 2020. https://doi:10.32388/WPP19W.4. 